\title{
PinX1 without the G-patch motif suppresses proliferation, induces senescence, but does not inhibit telomerase activity in colorectal cancer $\mathrm{SW480}$ cells
}

\author{
RUI ZHANG, JIAN ZHAO, XU WANG, LI-LI WANG, JIAN XU and CHUN SONG \\ Department of Colorectal Surgery, Liaoning Cancer Hospital and Institute, Shenyang, Liaoning 110042, P.R. China
}

Received February 25, 2014; Accepted April 11, 2014

DOI: $10.3892 /$ or.2014.3199

\begin{abstract}
Evidence suggests that Pin2/TRF1-interacting protein $\mathrm{X} 1$ (PinX1) inhibits telomerase activity in many types of cancer cells. G-patch is a motif in the PinX1 protein; however, the function of G-patch in colorectal cancer cells has not been definitively elucidated. The present study investigated the antitumor activities of different PinX1 fragments in vitro, and explored the molecular mechanisms responsible for these effects. SW480 cells were transfected with pEGFP-A1-PinX1 1-328 (intact) or pEGFP-A1-PinX1 69-328 (truncated). Flow cytometry was used to observe apoptosis and the cell cycle of SW480 cells transfected with intact PinX1 or truncated PinX1. The apoptosis-related proteins, caspase 3, 8 and 9, were detected by western blotting. Our results indicate that both intact and truncated PinX1 induced apoptosis, $\mathrm{G}_{1}$ arrest, and cellular senescence. However, truncated PinX1 showed no effects on telomerase activity. Why PinX1 without G-patch has similar antitumor activities as intact PinX1 remains unclear. The mechanisms of G-patch require elucidation in subsequent studies. Finally, we detected the protein and mRNA levels of PinX1 and caspase 3,8 and 9 in colorectal cancer specimens and confirmed that levels of PinX1 and caspase 3, 8 and 9 expression were closely linked to the poor prognosis of colorectal cancer.
\end{abstract}

\section{Introduction}

Telomeres have many functions within cells, such as maintaining genomic stability and protecting the chromosomal ends from degradation $(1,2)$. Inhibition of telomerase activity or shortened telomeres may increase the incidence of cancer in aged cells (3). Pin2/TRF1-interacting protein X1 (PinX1) which consisting of seven axons is located at chromosome

Correspondence to: Dr Chun Song, Department of Colorectal Surgery, Liaoning Cancer Hospital and Institute, Shenyang, Liaoning 110042 , P.R. China

E-mail: csong2005@126.com

Key words: PinX1, apoptosis, colorectal cancer cells, caspase, cell cycle 8p23 (4). Its coding protein that contains 328 amino acids has 2 domains, one is G-patch found in RNA-binding proteins or damage repair agents, the second is telomerase inhibitory domain (TID) (4). In previous studies, it has been observed that PinX1 suppresses telomerase activity by its direct interaction with hTERT and hTR (5). Depletion of PinX1 results in lagging chromosome in mitosis and micronuclei in interphase (6). PinX1 is considered as a tumor suppressor in many tumors due to its low expression in hepatocellular carcinoma (7), prostate cancer (8), gastric carcinoma (9) and medulloblastomas (10).

Although much is known regarding the role of PinX1 in regulating telomerase function, less is known concerning the role of PinX1 without G-patch in colorectal cancer cells. The aim of the present study was to ascertain whether PinX1 without G-patch suppresses the growth of colorectal cancer cells.

\section{Materials and methods}

Cell culture and synchronization. SW480 cells [American Type Culture Collection (ATCC), Manassas, VA, USA] were maintained as subconfluent monolayers in Dulbecco's modified Eagle's medium (DMEM) (Invitrogen, Carlsbad, CA, USA) with $10 \%$ fetal bovine serum (FBS) (HyClone, Logan, UT, USA) and $100 \mathrm{U} / \mathrm{ml}$ penicillin plus $100 \mu \mathrm{g} / \mathrm{ml}$ streptomycin (Invitrogen) at $37^{\circ} \mathrm{C}$ with $5 \% \mathrm{CO}_{2}$. Cells were synchronized at $\mathrm{G}_{1} / \mathrm{S}$ with $5 \mathrm{mM}$ thymidine for $12-16 \mathrm{~h}$ and then washed with phosphate-buffered saline (PBS) three times and cultured in thymidine-free medium for $10 \mathrm{~h}$.

Plasmid construction and transfection. The cDNA encoding PinX1 was cloned into a pEGFP-A1 vector (reserved by our laboratory) to generate the pEGFP-A1-PinX1 plasmid. The PCR product for PinX1 69-328 was cut with restriction enzymes and then inserted into the pEGFP-A1. Transfection of plasmids into SW480 cells was performed using Lipofectamine 2000 (Invitrogen) according to the manufacturer's instructions.

Immunofluorescence. Cells were fixed with $4 \%$ paraformaldehyde, permeabilized with $0.5 \%$ Triton $\mathrm{X}$, then blocked with 2\% BSA in PBS. The primary PinX1 antibody (sc-376394, Epitope: 8-29; Santa Cruz Biotechnology, Santa Cruz, CA, USA) was used at a 1:100 concentration, and the secondary antibody was Alexa Fluor ${ }^{\circledR} 594$ rat anti-mouse $\operatorname{IgG}(\mathrm{H}+\mathrm{L})$ 
Table I. The primers used in the real-time PCR analyses.

\begin{tabular}{ll}
\hline Gene & \multicolumn{1}{c}{ Sequence (5'-3'; forward/reverse) } \\
\hline Pinx1 & ATGTCTATGCTGGCTGAA/ \\
TCTGTGGCTCCTTGCT & CTCGGTCTGGTACAGATGTCG/ \\
Caspase 3 & GGTTAACCCGGGTAAGAATG \\
TCTGGAGCATCTGCTGTCTG/ & CCTGCCTGGTGTCTGAAGTT \\
Caspase 9 & ATGGACGAAGCGGATCGG/ \\
& CCCTGGCCTTATGATGTT \\
GAPDH & TGGTATCGTGGAAGGACTCATGAC/ \\
& ATGCCAGTGAGCTTCCCGTTCAGC
\end{tabular}

antibody at a concentration of 1:500. Cells were examined and photographed using an Olympus CX71 fluorescence microscope (Olympus, Tokyo, Japan).

MTT assay. Viability of the cells was determined using 3-(4,5-dimethylthiazolyl)-2,5-diphenyltetrazolium bromide (MTT) assay (Sigma-Aldrich, Carlsbad, CA, USA). Cells were plated in 96-well plates (1,500 cells/well) and incubated under normal culture conditions. After $48 \mathrm{~h}$, the cells described above were treated with $0.5 \mathrm{mg} / \mathrm{ml}$ of MTT for $4 \mathrm{~h}$ and lysed with dimethyl sulfoxide (DMSO). Absorbance rates were measured at 550-560 $\mathrm{nm}$ using a microplate reader (Bio-Rad, Hercules, CA, USA).

Annexin V-FITC and propidium iodide (PI) double staining. Annexin V-FITC/PI double staining assays were performed to detect apoptosis. Following the manufacturer's instructions (Apoptosis Detection kit; KeyGen, Nanjing, China), cells were washed and resuspended in binding buffer prior to the addition of FITC-labeled Annexin V and PI for $10 \mathrm{~min}$. Suspensions were immediately analyzed by flow cytometry using a FACSCalibur machine (BD Biosciences, Baltimore, MD, USA).

Cell cycle study. Cells were suspended in PBS and then fixed with $70 \%$ ethanol at $4^{\circ} \mathrm{C}$. After centrifugation, the supernatants were discarded, and cellular DNA was stained in a solution containing $10 \mu \mathrm{M}$ of propidium iodide (KeyGen). Then the mixture was analyzed by a FACSCalibur flow cytometer (Becton-Dickinson).

SA- $\beta$-gal analysis. For SA- $\beta$-gal staining, cells were washed twice in PBS, fixed for 3-5 min at room temperature in $3 \%$ formaldehyde and washed again with PBS. Then cells were incubated overnight at $37^{\circ} \mathrm{C}$ without $\mathrm{CO}_{2}$ in a freshly prepared SA- $\beta$-gal-staining solution as described (11).

TRAP telomerase activity assay. Cells were lysed in lysis buffer (10 mM Tris- $\mathrm{HCl} \mathrm{pH}, 7.5,1 \mathrm{mM} \mathrm{MgCl} \mathrm{M}_{2}, 1 \mathrm{mM}$ EGTA, $0.1 \mathrm{mM}$ PMSF, 5 mM 2-mercaptoethanol, $0.5 \%$ CHAPS, $10 \%$ glycerol) on ice for $30 \mathrm{~min}$ and then centrifuged at high speed

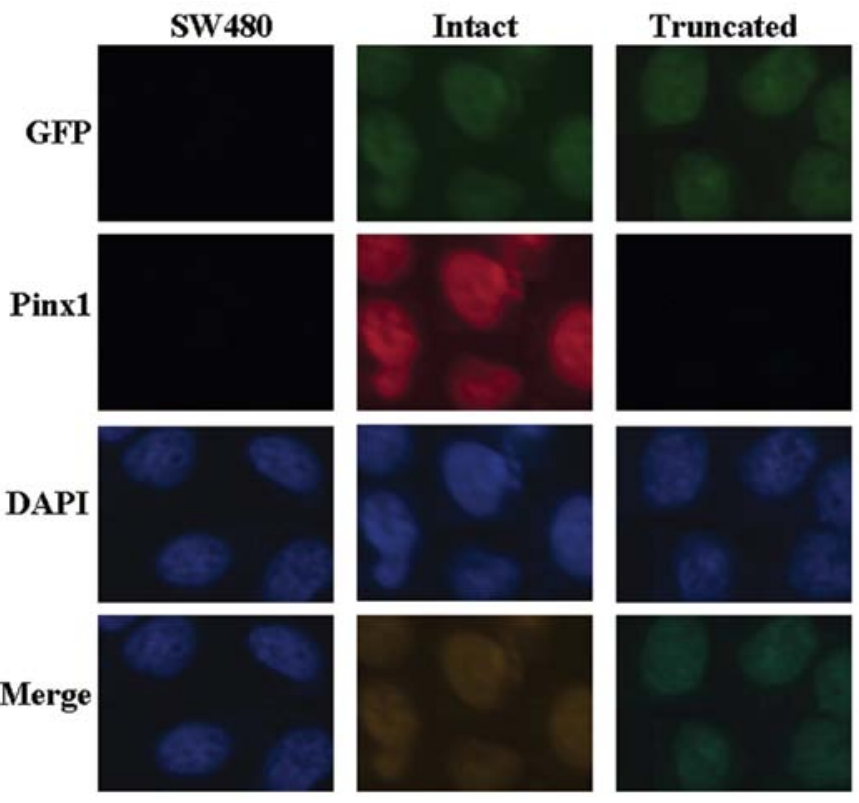

Figure 1. Confirmation of exogenous PinX1 expression in SW480 cells. Cells were transfected with pEGFP-A1-PinX1 1-328 or pEGFP-A1-PinX1 69-328, and immunofluorescence was performed with the indicated antibody. Immunofluorescence showed localization of PinX1 and EGFP in the PinX1-expressing SW480 cells. SW480, untreated SW480 cells; intact, SW480 cells transfected with pEGFP-A1-PinX1 1-328; truncated, SW480 cells transfected with pEGFP-A1-PinX1 69-328.

for $30 \mathrm{~min}$, the suspension containing telomerase was used for TRAP assay. Telomerase activity was measured with the TRAPeze telomerase detection kit (Chemicon, Temecula, CA, USA) according to the manufacturer's instructions (12).

Subjects. A total of 52 patients with colorectal cancer were obtained from the Department of Colorectal Surgery, Liaoning Cancer Hospital and Institute (January 2008 to December 2012). All patients underwent standard laboratory tests (cytology and histology). None of the patients underwent radiotherapy or chemotherapy before the operation. Informed consent was provided by all patients according to the Helsinki Declaration.

Extraction of total RNA and real-time PCR.RNA was extracted from tissues using TRIzol solution (Invitrogen) according to the protocols recommended by the manufacturer. Total RNA concentration and quantity were assessed by absorbency at $260 \mathrm{~nm}$ using a DNA/Protein Analyzer (DU 530; Beckman, Fullerton, CA, USA). Real-time PCR was performed on a Rotor-Gene RG-6000A apparatus (Corbett Research, Cambridge, UK) for 40 cycles of $94^{\circ} \mathrm{C}$ for $10 \mathrm{sec}, 60^{\circ} \mathrm{C}$ for $10 \mathrm{sec}$ and $72^{\circ} \mathrm{C}$ for $15 \mathrm{sec}$. Reactions $(20 \mu \mathrm{l})$ included $2 \mu \mathrm{l}$ of cDNA, target-specific primers, and the QuantiTect SYBRGreen PCR kit (Qiagen, Valencia, CA, USA). The temperature range for analysis of the melting curves was $55-99^{\circ} \mathrm{C}$ over $30 \mathrm{sec}$. The primer sequences are listed in Table I. Relative quantitation was calculated using the $\Delta \Delta \mathrm{Ct}$ method.

Western blot analysis. Cells or tissues were lysed in lysis buffer (20 mM Tris-HCl, $150 \mathrm{mM} \mathrm{NaCl}, 2$ mM EDTA, 1\% Triton X-100) containing a protease inhibitor cocktail (Sigma). 
A

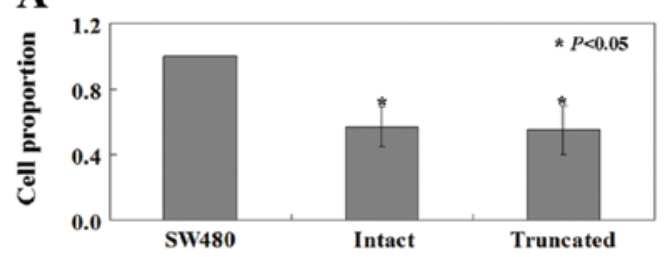

B
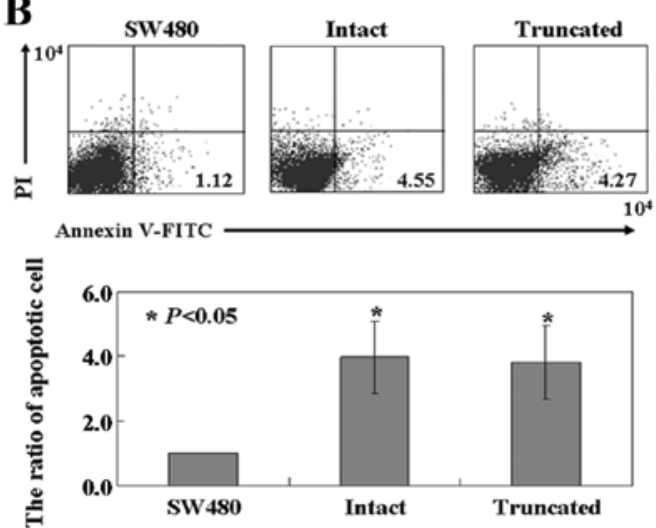

D

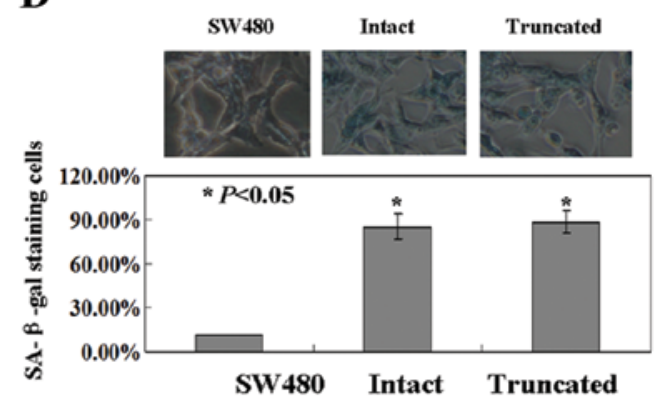

$\mathbf{E}$

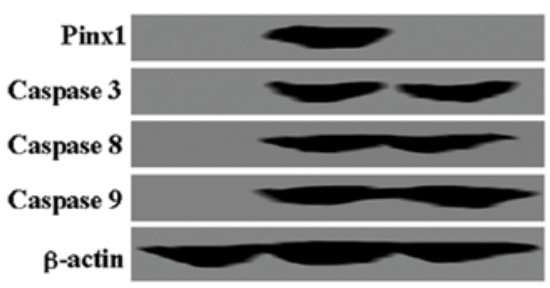

F

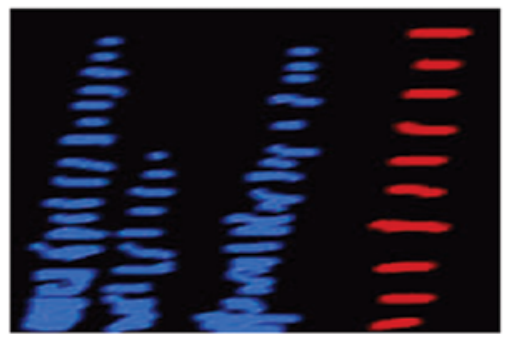

SW480 Intact Truncated Marker

Figure 2. Antitumor activities of PinX1 fragments in SW480 cells. (A) Proliferation ratio of SW480 cells transfected with pEGFP-A1-PinX1 1-328 or pEGFP-A1-PinX1 69-328 was measured using an MTT assay. (B) Apoptotic ratio of cells was analyzed by double staining with Annexin-V/propidium iodide (PI). (C) PI staining showed changes in the cell cycle. (D) SW480 cells transfected with pEGFP-A1-PinX1 1-328 or pEGFP-A1-PinX1 69-328 were stained for SA-b-gal activity. (E) Western blot analysis of apoptosis-related proteins. PinX1, caspase 3, 8 and 9 were detected by western blot analysis. $\beta$-actin was used as an internal control. (F) Intact PinX1-transfected SW480 cells showed reduced telomerase activity and truncated PinX1 displayed robust telomerase activity.

Cell extract protein amounts were quantified using the BCA protein assay kit. Equivalent amounts of protein $(30 \mu \mathrm{g})$ were separated using $12 \%$ SDS-PAGE and transferred to a PVDF membrane (Millipore Corporation, Billerica, MA, USA). Anti-Pinx1 antibody (Santa Cruz) was used to identify transfection efficiency, and detection of $\beta$-actin was used as an internal control. Cell apoptosis-related proteins were also probed using the following antibodies (Santa Cruz): caspase 3,8 and 9. Binding of each specific antibody was detected with horseradish peroxidase (HRP)-conjugated respective secondary antibodies and ECL solutions (both from Amersham Biosciences, UK).

Immunohistochemical studies. Excised tumors were fixed in $4 \%$ paraformaldehyde for $24 \mathrm{~h}$ then embedded in paraffin. Sections $(4-\mu \mathrm{m})$ were generated for immunohistochemical staining. Endogenous peroxidase activity was blocked by incubating sections in 3\% hydrogen peroxide for $30 \mathrm{~min}$. Antigen retrieval was performed in citrate buffer $(10 \mathrm{mM}, \mathrm{pH}, 6.0)$ for $30 \mathrm{~min}$ at $95^{\circ} \mathrm{C}$ in a pressure cooker (YQ50-90A; Peskoe ${ }^{\circledR}$, Guangzhou, China). Antibodies described for western blot analysis were applied, and sections were incubated at $4{ }^{\circ} \mathrm{C}$ overnight. Sections were washed with PBS and then incubated with a biotinylated secondary antibody at $37^{\circ} \mathrm{C}$ for $2 \mathrm{~h}$ and then exposed to a streptavidin complex (HRP; Beyotime, Beijing). Positive reactions were visualized using 3,3'-diaminobenzidine tetrahydrochloride (DAB), followed by counterstaining with hematoxylin (both from Beyotime).

Statistical analysis. The Statistical Package for the Social Sciences 16.0 software (SPSS, Chicago, IL, USA) was used for statistical analyses. Kaplan-Meier survival plots were generated, and comparisons were made with log-rank statistics. Data are expressed as the means $\pm \mathrm{SD}$, and the intergroup difference was compared using the Student's t-test. A P-value $<0.05$ was considered to indicate a statistically significant result.

\section{Results}

PinX1-expressing SW480 cell line. We investigated the consequence of exogenous PinX1 expression in SW480 cells. SW480 cells were transfected with pEGFP-A1-PinX1 1-328 or pEGFP-A1-PinX1 69-328, and $\mathrm{EGFP}^{+} \mathrm{SW} 480$ cells were measured by immunofluorescence analysis. As shown in Fig. 1, immunofluorescence analysis showed the localization of PinX1 and EGFP in the PinX1-expressing SW480 cells. 
A

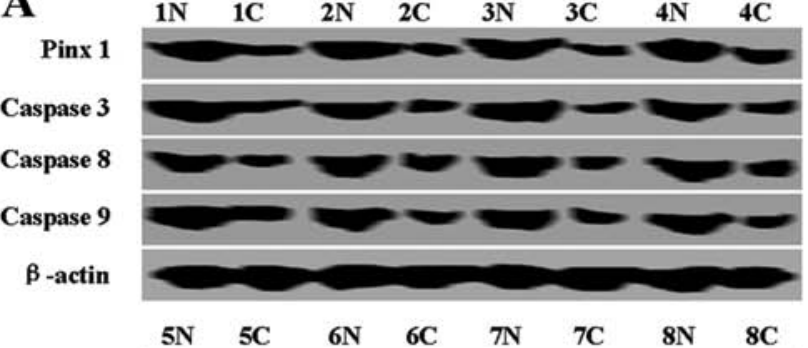

Pinx 1

Caspase 3

Caspase 8

Caspase 9

$\beta$-actin
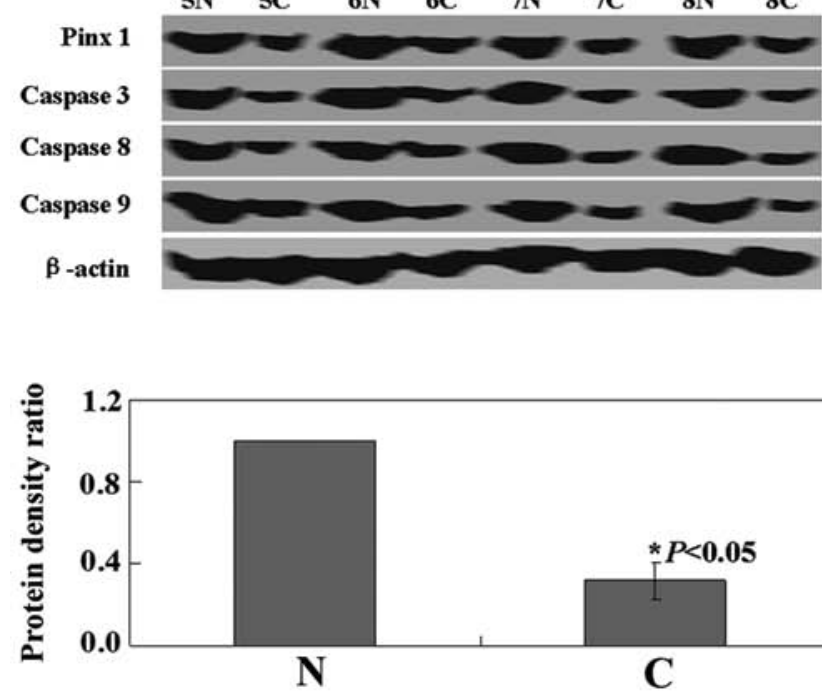

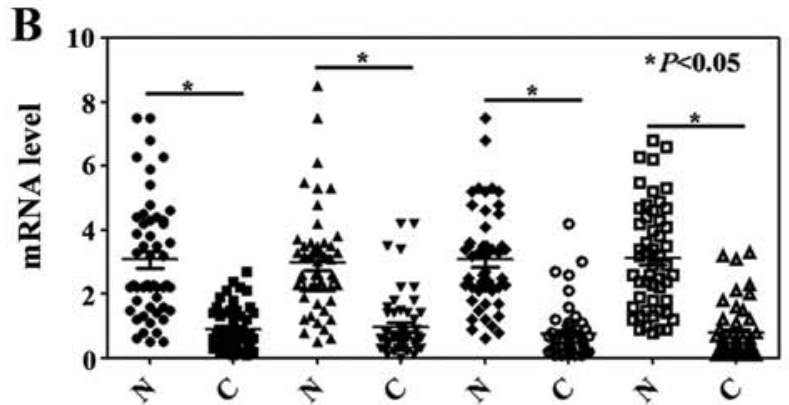

Pinx 1 Caspase 3 Caspase 8 Caspase 9

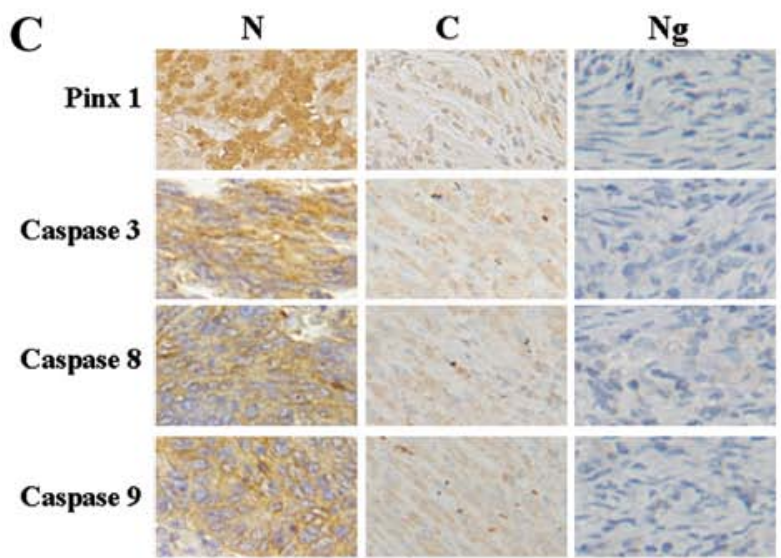

Figure 3. Levels of PinX1 and caspase 3, 8 and 9 proteins in colorectal cancer tissues. (A) Representative results of PinX1 and caspase 3, 8 and 9 expression in 8 paired colorectal cancer and corresponding normal tissues by western blotting. $\beta$-actin was used as an internal control. (B) The levels of PinX1 and caspase 3 , 8 and 9 mRNA were measured in specimens using real-time PCR. GAPDH was used as an internal control. (C) Immunohistochemical staining for PinX1 and caspase 3, 8 and 9 protein in specimens. The nuclei were counterstained with hematoxylin. $\mathrm{N}$, normal; $\mathrm{C}$, cancer; $\mathrm{Ng}$, negative control.

Effects of PinX1 or PinX1 69-328 on SW480 cells. Cell viability was monitored using an MTT assay, and the results indicated that the proliferation ratio of SW480 cells was inhibited by both PinX1 and PinX1 69-328 (P<0.05, Fig. 2A). We utilized Annexin V-FITC and PI double staining to detect apoptotic cells. The apoptotic ratio was 3.8- to 4.2 -fold higher in the cells expressing intact or truncated PinX1 when compared with the ratio of the untransfected cells $(\mathrm{P}<0.05$, Fig. 2B). When the cell cycle distribution of the transfected and untransfected cells was examined using PI staining, the ratio of cells in the $G_{1}$ phase was found to be increased in cells expressing intact or truncated PinX1 vs. the untransfected cells $(\mathrm{P}<0.05$, Fig. 2C). Intact or truncated PinX1-transfected SW480 cells showed strong levels of blue SA- $\beta$-gal staining when compared with the untransfected cells $(\mathrm{P}<0.05$, Fig. 2D). Levels of caspase 3,8 and 9 protein were significantly increased in the SW480 cells following PinX1 or PinX1 69-328 treatment (Fig. 2E). We next examined telomerase activity in the intact or truncated PinX1-transfected SW480 cells and found that the intact PinX1-transfected SW480 cells showed reduced telomerase activity, while the truncated PinX1-transfected cells displayed robust telomerase activity. In contrast, there was no significant change in the telomerase activity in the untransfected cells as observed by TRAP assay (Fig. 2F).

PinX1 or caspase expression in human colorectal cancer specimens and the clinicopathological variables. Western blot analysis was performed in order to determine the

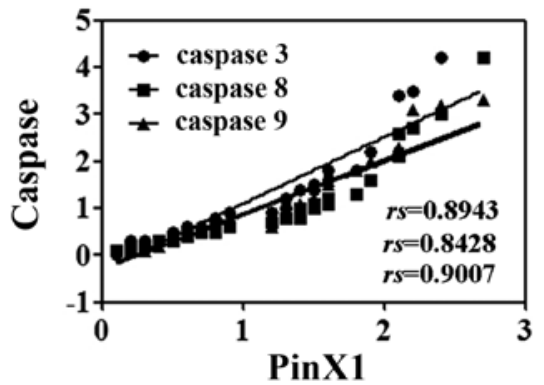

Figure 4. Positive correlation between the protein levels of PinX1 and caspase 3, 8 and 9 in the patients with colorectal cancer. PinX1, Pin2/TRF1interacting protein $\mathrm{X} 1$.

protein expression levels of PinX1, caspase 3, 8 and 9. PinX1, caspase 3,8 and 9 protein levels in the cancer tissues were significantly lower than levels in the normal tissues ( $\mathrm{P}<0.05$, Fig. 3A). Real-time PCR analysis for PinX1 and caspase 3, 8 and 9 mRNA was performed in 52 colorectal cancer specimens. Results showed that the levels of PinX1 and caspase 3, 8 and 9 mRNA in cancer tissues were significantly lower than the levels in the normal tissues $(\mathrm{P}<0.05$, Fig. 3B). The results of immunohistochemistry showed that caspase 3,8 and 9 protein was localized in the cytoplasm, while PinX1 protein was localized in the nucleus of the cells (Fig. 3C). The protein levels of PinX1 and caspase 3, 8 and 9 were significantly positively correlated $(\mathrm{P}<0.05$, Fig. 4$)$. We then analyzed the 


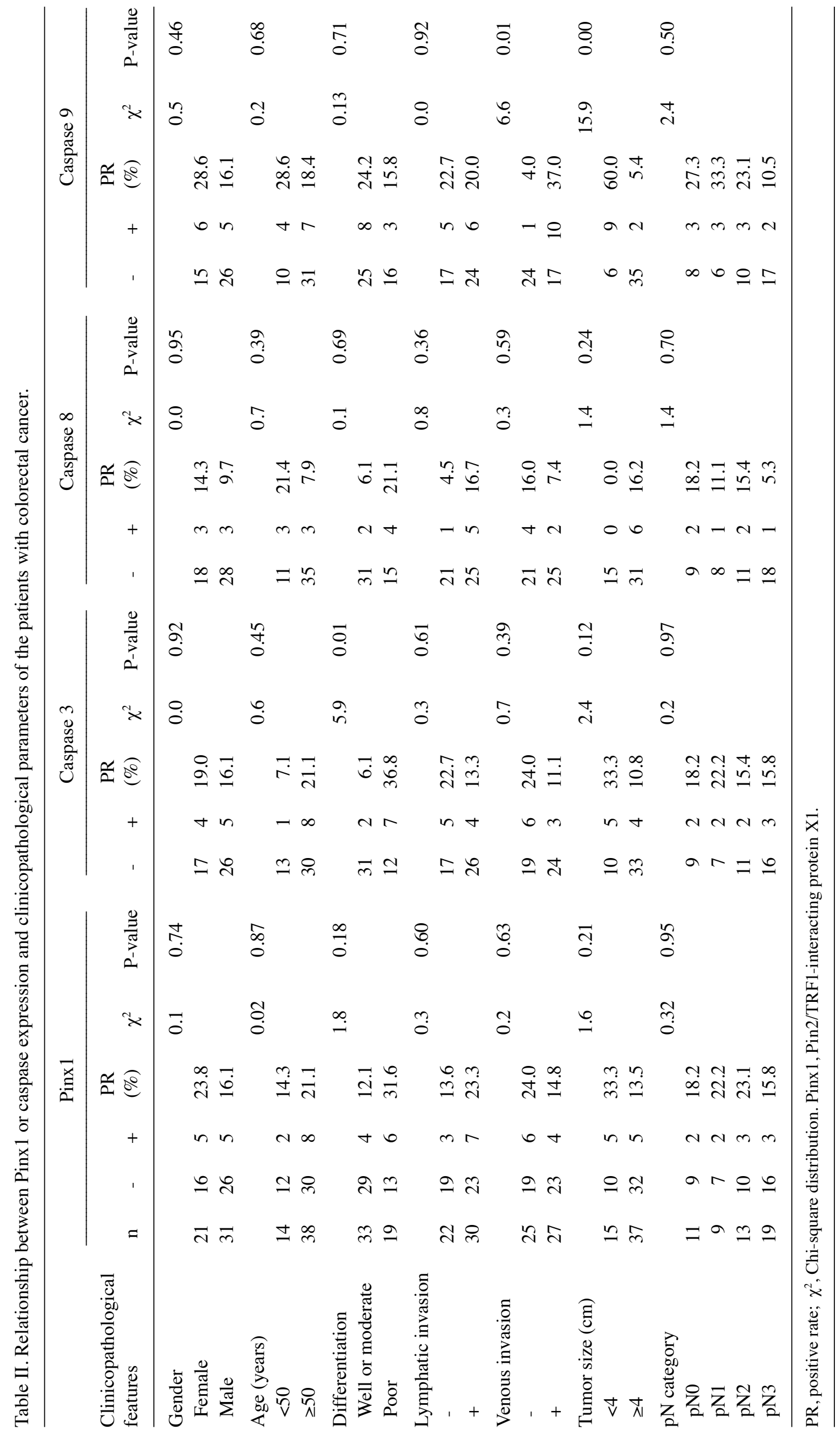



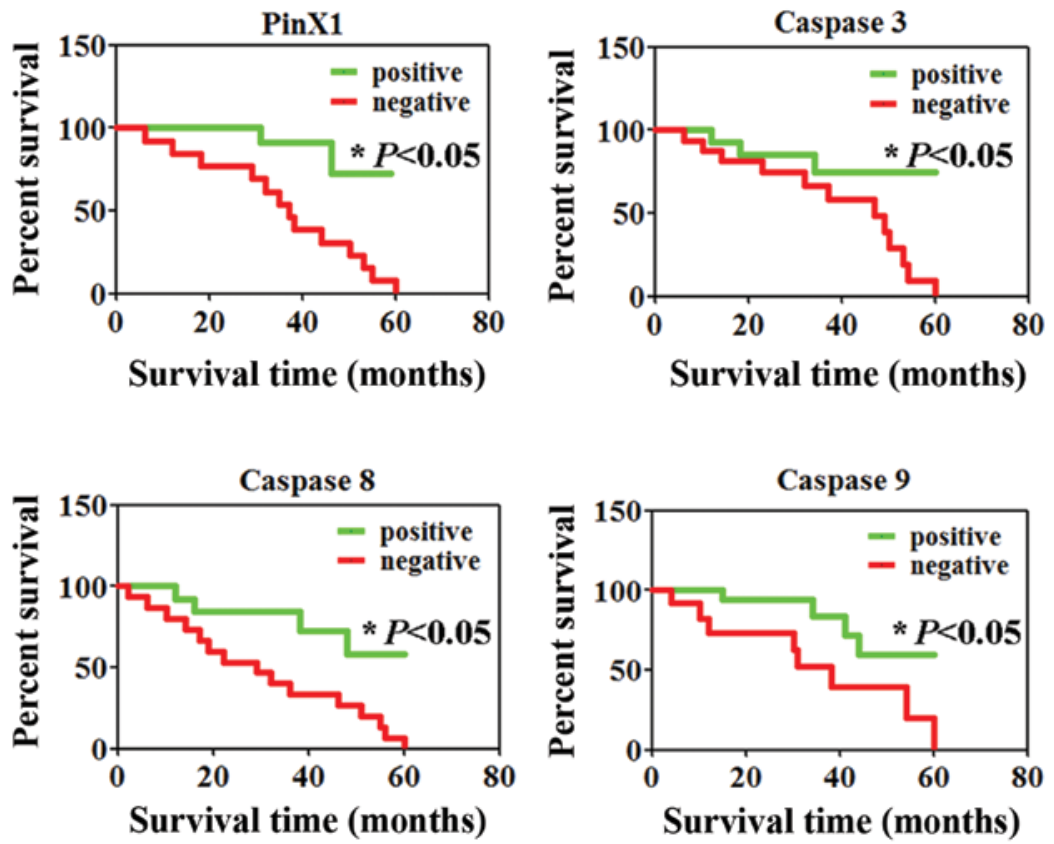

Figure 5. Kaplan-Meier curves of the cumulative survival rate of patients with gastric cancer based on PinX1 or caspase 3, 8 and 9 expression.

potential relationship between the expression of PinX1 and caspase 3,8 and 9 and the clinicopathological characteristics of these patients. Unfortunately, we only found that caspase 3 was associated with differentiation, and caspase 9 was associated with venous invasion and tumor size $(\mathrm{P}<0.05$, Table II). Finally, we investigated the level of PinX1 and caspase 3,8 and 9 with patient survival. Comparison by the Kaplan-Meier method for low vs. high PinX1 or caspase 3,8 and 9 expression showed a significant difference in the 5-year survival rate of the patients with colorectal cancer $(\mathrm{P}<0.05$, Fig. 5).

\section{Discussion}

As noted in the Introduction, Pin2/TRF1-interacting protein $\mathrm{X} 1$ (PINX1) is a co-regulating gene of telomerase and telomere (7), which is located at chromosome 8p23, consisting of seven axons with two transcription pathways encoding 174 aa and 328 aa proteins (4). In the present study, we demonstrated that PinX1 could induce apoptosis, $\mathrm{G}_{1}$ arrest, and cellular senescence in colorectal cancer SW480 cells. In addition, we revealed that intact PinX1 (1-328 aa) inhibited telomerase activity in the SW480 cells. Previous studies also showed that PinX1 is an internal telomerase inhibitor and suppresses tumor growth both in vivo and in vitro (13-15). Overexpression of PinX1 in tumor cells could inhibit telomerase activity, shorten telomeres, and suppress tumor growth, while depletion of endogenous PinX1 increased telomerase activity, elongated telomeres, and enhanced tumorigenicity in a fibrosarcoma cell line, HT1080 (4). However, to our knowledge, no studies have shown the functions of the G-patch motif in PinX1. Notably, in the present study, we found that PinX1 without G-patch (69-328 aa) induced apoptosis and $\mathrm{G}_{1}$ arrest but showed no effects on telomerase activity.

In budding yeast, the PinX1 homolog Gnop1 was shown to bind the yeast telomerase catalytic protein Est2p and inhibit telomerase (16). Gnop1 has additional functions in processing ribosomal RNA and other small nucleolar RNAs that are mediated, at least in part, through G-patch $(17,18)$. However, the effect of human PinX1 on telomerase appears to be exclusive of the G-patch region and is mediated instead by the $\mathrm{C}$ terminus of the protein (4). Thus, combined with our results, these findings suggested that the interaction with hTR cannot be ascribed to a general RNA binding feature of PinX1 mediated through G-patch. However, why the PinX1 without G-patch has similar antitumor activities as intact PinX1 remains unclear. The mechanisms of G-patch warrant elucidation in further studies.

\section{Acknowledgements}

This study was supported by the Natural Science Foundation of Liaoning Province, China (grant no. 2013020158).

\section{References}

1. Blackburn EH: Switching and signaling at the telomere. Cell 106: 661-673, 2001.

2. de Lange T: Protection of mammalian telomeres. Oncogene 21: 532-540, 2002.

3. Smogorzewska A and de Lange T: Regulation of telomerase by telomeric proteins. Annu Rev Biochem 73: 177-208, 2004.

4. Zhou XZ and Lu KP: The Pin2/TRF1-interacting protein PinX1 is a potent telomerase inhibitor. Cell 107: 347-359, 2001.

5. Banik SS and Counter CM: Characterization of interactions between PinX1 and human telomerase subunits hTERT and hTR. J Biol Chem 279: 51745-51748, 2004.

6. Yuan K, Li N, Jiang K, et al: PinX1 is a novel microtubule-binding protein essential for accurate chromosome segregation. J Biol Chem 284: 23072-23082, 2009.

7. Park WS, Lee JH, Park JY, et al: Genetic analysis of the liver putative tumor suppressor (LPTS) gene in hepatocellular carcinomas. Cancer Lett 178: 199-207, 2002.

8. Hawkins GA, Chang B, Zheng SL, et al: Mutational analysis of PINX1 in hereditary prostate cancer. Prostate 60: 298-302, 2004. 
9. Kondo T, Oue N, Mitani Y, et al: Loss of heterozygosity and histone hypoacetylation of the PINXI gene are associated with reduced expression in gastric carcinoma. Oncogene 24: 157-164, 2005.

10. Chang Q, Pang JC, Li J, Hu L, Kong X and Ng HK: Molecular analysis of PinX1 in medulloblastomas. Int $\mathrm{J}$ Cancer 109: 309-314, 2004.

11. Dimri GP, Lee X, Basile G, et al: A biomarker that identifies senescent human cells in culture and in aging skin in vivo. Proc Natl Acad Sci USA 92: 9363-9367, 1995.

12. Kim NW, Piatyszek MA, Prowse KR, et al: Specific association of human telomerase activity with immortal cells and cancer. Science 266: 2011-2015, 1994.

13. Qian D, Zhang B, He LR, et al: The telomere/telomerase binding factor PinX1 is a new target to improve the radiotherapy effect of oesophageal squamous cell carcinomas. J Pathol 229: 765-774, 2013.
14. Lai XF, Shen CX, Wen Z, et al: PinX1 regulation of telomerase activity and apoptosis in nasopharyngeal carcinoma cells. J Exp Clin Cancer Res 31: 12, 2012

15. Liu JY, Qian D, He LR, et al: PinX1 suppresses bladder urothelial carcinoma cell proliferation via the inhibition of telomerase activity and p16/cyclin D1 pathway. Mol Cancer 12: 148, 2013.

16. Lin J and Blackburn EH: Nucleolar protein PinX1p regulates telomerase by sequestering its protein catalytic subunit in an inactive complex lacking telomerase RNA. Genes Dev 18: 387-396, 2004.

17. Guglielmi B and Werner M: The yeast homolog of human PinX1 is involved in rRNA and small nucleolar RNA maturation, not in telomere elongation inhibition. J Biol Chem 277: 35712-35719, 2002.

18. Aravind L and Koonin EV: G-patch: a new conserved domain in eukaryotic RNA-processing proteins and type D retroviral polyproteins. Trends Biochem Sci 24: 342-344, 1999. 